\title{
Optimized 3-step Skew Spoke Type BLAC Motor Cogging Torque Reduction Technique for EPS Application
}

\author{
S. Saha, S.A. Kim, Y.H. Cho \\ Department of Electrical Engineering, Dong-A University \\ South Korea
}

\begin{abstract}
In electric power steering (EPS), spoke type brushless ac (BLAC) motors offer distinct advantages over other electric motor types in terms torque smoothness, reliability and efficiency. This paper deals with the shape optimization of spoke type BLAC motor, in order to reduce cogging torque. This paper examines 3 step skewing rotor angle, optimizing rotor core edge and rotor overlap length for reducing cogging torque in spoke type BLAC motor. The methods were applied to existing machine designs and their performance was calculated using finite- element analysis (FEA). Prototypes of the machine designs were constructed and experimental results obtained. It is shown that the FEA predicted the cogging torque to be nearly reduce using those method.
\end{abstract}

Keywords- EPS; 3-step skewing; spoke type BLAC; cogging torque; FEA

\section{INTRODUCTION}

The cogging torque and its reduction techniques in PM brushless AC machines have been broadly investigated over the past decades. Up to date, there have been various studies devoted to 3-D analytical modeling and prediction of cogging torque in surface- mounted PM brushless machines with regular geometric shapes [6], [7] and the versatile finiteelement analysis (FEA) is widely employed to evaluate the cogging torque in all kinds of PM brushless AC machines [8][9].Recently brushless spoke type machines are becoming increasingly popular in industrial applications. They offer a highly efficient, high power-density, low size alternative to conventional machines, and as their cost continues to decrease they have the opportunity to become a dominant force in the industrial applications market [1], [2]. One major drawback to spoke type machines is the torque ripple that is inherent in their design. This ripple is parasitic, and can lead to mechanical vibration, acoustic noise, and problems in drive systems. Minimizing this ripple is of great importance in the design of a BLAC spoke type machine [3].

However, in many case of vehicle applications, a cogging torque of the electric motor is of basic concern. There is no exception for the BLAC motor employed as the EPS system. Therefore, the cogging torque minimization of the BLAC motor is becoming necessary since its low torque ripple is required in the EPS application. This paper presents the rotor shape optimization of a 3-step skewing [5] spoke type BLAC motor, which is designed for an electric power steering application. The design specification of the BLAC motor for the EPS application is listed in TABLE I, and proto type of the spoke type BLAC motor is illustrated in Fig. 1(a).

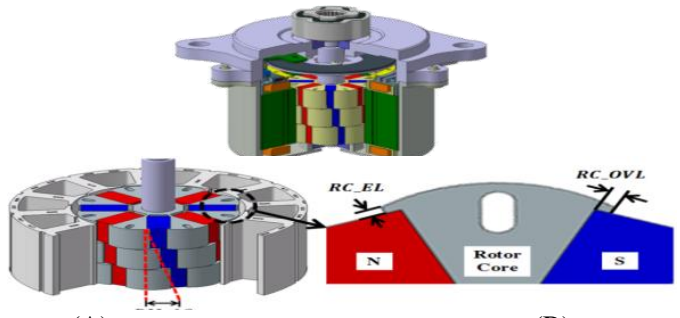

(A)

(B)

FIGURE I. (A) PROTO TYPE 3-STEP SKEWING SPOKE TYPE BLAC MOTOR, (B) ROTOR SKEW MODEL FOR MINIMIZING COGGING TORQUE.

TABLE I. MAIN DESIGN PARAMETERS OF PROTOTYPE SPOKE TYPE BLAC MOTOR.

\begin{tabular}{|c|c|c|c|c|c|}
\hline $\begin{array}{c}\text { Sym } \\
\text { bol }\end{array}$ & Item & $\begin{array}{l}\text { Val } \\
\text { ue }\end{array}$ & $\begin{array}{c}\text { Symb } \\
\text { ol }\end{array}$ & Item & Value \\
\hline- & $\begin{array}{c}\text { Phase } \\
\text { number }\end{array}$ & 3 & $g$ & Air gap length & 0.62 \\
\hline$p_{s}$ & $\begin{array}{l}\text { Stator slot } \\
\text { number }\end{array}$ & 12 & $V$ & Voltage & 12 \\
\hline$p_{r}$ & $\begin{array}{l}\text { Rotor slot } \\
\text { number }\end{array}$ & 8 & $T_{r}$ & Rated Torque & 3.26 \\
\hline$N$ & $\begin{array}{l}\text { Coil turn } \\
\text { number }\end{array}$ & 24 & & Rated Current & 70 \\
\hline$P M$ & $\begin{array}{l}\text { Magnet } \\
\text { material }\end{array}$ & $\begin{array}{l}\text { Ferr } \\
\text { ite }\end{array}$ & $l_{a}$ & Stack length & 39 \\
\hline$D_{s o}$ & $\begin{array}{c}\text { Stator outer } \\
\text { diameter } \\
{[\mathrm{mm}]}\end{array}$ & 88.8 & - & Rotor type & $\begin{array}{l}\text { Spoke with } \\
\text { non- } \\
\text { embedded } \\
\text { magnets }\end{array}$ \\
\hline$D_{r o}$ & $\begin{array}{c}\text { Rotor outer } \\
\text { diameter } \\
{[\mathrm{mm}]}\end{array}$ & 50.8 & $P_{r}$ & Rated Power & 420 \\
\hline - & Stator type & $\begin{array}{l}\text { squ } \\
\text { are }\end{array}$ & $n_{r}$ & $\begin{array}{c}\text { Rated rotational } \\
\text { speed }\end{array}$ & 1230 \\
\hline
\end{tabular}

\section{REDUCING COGGING TORQUE}

In its most fundamental form, cogging torque can be represented by

$$
T_{\operatorname{cog}}=-\frac{1}{2} \phi_{g}^{2} \frac{d R}{d \theta}
$$

Where $\phi_{g}$ is the air-gap flux, $R$ is the air-gap reluctance, and $\theta$ is the position of the rotor [4]. This supports the idea that cogging torque is the interaction between the magnets (the 
source of the air-gap flux since cogging torque is considered with an unexcited stator) and the stator teeth (the source of the varying air-gap reluctance). The air-gap reluctance varies periodically, thus causing the cogging torque to be periodic [7]. Because of this periodicity, cogging torque can be expressed as a Fourier series:

$$
T_{c o g}=\sum_{k=1}^{\infty} T_{m k} \sin (m k \theta)
$$

Where $m$ is the least common multiple of the number of stator slots $\left(p_{s}\right)$ and the number of poles $\left(N_{p}\right), k$ is an integer, and $T_{m k}$ is a Fourier coefficient [2]. It is seen that the cogging torque has $m$ periods per mechanical revolution of the rotor and has a direct relationship to the number of slots and pole. To theoretically eliminate cogging torque via machine design, one must examine the equations that define it. From the inspection of (1), it is seen that cogging torque can be eliminated by forcing either the air-gap flux, $\phi_{g}$ or the rate of change of the air-gap reluctance, $\frac{d R}{d \theta}$ to be zero. Making $\phi_{g}$ zero is not possible since the air-gap flux is needed for the alignment and reluctance torque components that drive the machine. Therefore, cogging torque can be cancelled by forcing the air-gap reluctance to be constant with respect to rotor position. In practice, cogging torque cannot be easily eliminated, but it can be greatly reduced [1].

\section{DECISION OF DESIGN VARIABLES}

The combination of rotor pole number and stator slot number can be optimized to reduce the cogging torque in PM brushless AC machines. Moreover, in this paper other cogging torque minimization techniques can be mainly categorized of rotor design. The rotor design based include rotor core edge length (RC_EL), rotor overlap length (RC_OVL) and PM rotor step skew angle (PM_AG) are illustrated in Fig. 1 (b). However, it is usually more preferable to implement rotor design based techniques than the stator design based ones to reduce the cogging torque due to the simpler rotor structure in PM brushless AC machines. The cogging torque could be virtually eliminated by uniformly 3 step skewing the stator slots by the angle of one cogging torque period, which is rather difficult to implement in the wound stator. Alternatively, continuously step skewing the simpler rotor by the same angle could be employed instead with equivalent results. However, continuous rotor skewing will inevitably results in magnets with irregular shapes, which are normally very expensive and even impractical to fabricate and magnetize. Consequently, a variant and alternative from called rotor 3 step skewing, which skews the rotor axially by certain discrete steps and hence eases the construction and assembly of the rotor.

$$
T_{c}(\theta)=\sum_{n=1}^{\infty} \sum_{k=0}^{p_{s}-1} \frac{\sin \left(\frac{\tau}{2} n p_{r} \theta_{s}\right)}{\tau \sin \left(\frac{n}{2} p_{r} \theta_{s}\right)} \cos \left(\frac{2 k n p_{r} \pi}{p_{s}}\right) T_{c s n} \sin \left(n p_{r} \theta\right)
$$

Where $\tau$ and $\theta_{s}$ are the skewing step number and mechanical skewing angle between the adjacent two steps. By inspection, all the harmonics of the cogging torque can virtually be eliminated except those which are multiples of $\tau$ with the step skewing angle as:

$$
\theta_{s}=\frac{2 k \pi}{\tau \operatorname{lcm}\left(N_{r}, N_{s}\right)}, \quad \mathrm{k}=1,2,3 \ldots
$$

Where $k$ normally should be kept as small as unity in order to prevent the machine performance from excessive deterioration. Based on the 2-D FEA results, the initial cogging torque and after optimization waveform of the machine with rotor 3 step skewing and corresponding step skewing angle from (4) is derived in Fig. 1 (b).

\section{OPTIMIZATION TECHNIQUE BY USING RSM METHOD}

The Cogging torque of the spoke type BLAC motor is complicated due to the influence of excessive magnetic saturation. Therefore, the finite element method (FEM) is adopted as a magnetic field analysis method, and the computational optimization has become indispensable for the electric machine design [9]-[10]. Therefore, in the proposed approach, the FEA is employed to analysis a magnetic field of the BLAC motor, the response surface method (RSM) is used to formulate the objective to reduce the cogging torque. The RSM is well adapted to make a systematic model for a complex problem, and the RSM provides a response surface of the overall behavior of design variables within a design space. In order to apply RSM technique for optimization the method describe in details in [11]-[12] are utilized. The expression of response surface is commonly used as a second-order polynomial representation and it can be written as follows:

$$
y=\beta_{0}+\sum_{i=1}^{n} \beta_{i} x_{i}+\sum_{i=1}^{n} \beta_{i i} x_{i}^{2}+\sum_{i \neq j}^{n} \beta_{i j} x_{i} x_{j}+\varepsilon
$$

Where $n$ is the number of design variables, $\beta$ is regression coefficients, $\varepsilon$ denotes the error estimate, and $y$ can be the cogging torque, the coefficient of the back-EMF From the configuration of the initial shape of the motor shown in Fig. 1 (b), three design variables are chosen for the reduction of the cogging torque. The design parameters, from $x_{1}$ to $x_{3}$, are described in Fig.2: " $x_{1}$ " permanent magnet skew angle, " $x_{2}$ " Rotor core edge-length; " $x_{3}$ " rotor overlap length.

TABLE II. DESIGN AREA FOR SPOKE TYPE BLAC MOTOR.

\begin{tabular}{ccc}
\hline $\begin{array}{c}\text { Permanent magnet skew } \\
\text { angle (PM_AG) }: \boldsymbol{x}_{\mathbf{1}}\end{array}$ & $\begin{array}{c}\text { Rotor core edge- } \\
\text { length (RC_EL) } \\
\boldsymbol{x}_{\mathbf{2}}\end{array}$ & $\begin{array}{c}\text { Rotor overlap length } \\
\text { (RC_OVL): } \boldsymbol{x}_{\mathbf{3}}\end{array}$ \\
\hline $6^{\circ}$ & $1.0 \mathrm{~mm}$ & $1.9 \mathrm{~mm}$ \\
$8^{\circ}$ & $1.1 \mathrm{~mm}$ & $2.0 \mathrm{~mm}$ \\
$10^{\circ}$ & $1.2 \mathrm{~mm}$ & $2.1 \mathrm{~mm}$ \\
$12^{\circ}$ & $1.3 \mathrm{~mm}$ & $2.2 \mathrm{~mm}$ \\
$13^{\circ}$ & $1.4 \mathrm{~mm}$ & $2.3 \mathrm{~mm}$ \\
$14^{\circ}$ & $1.5 \mathrm{~mm}$ & $2.4 \mathrm{~mm}$ \\
\hline
\end{tabular}

TABLE III. OBSERVED RESPONSES OBTAINED BY FEM.

\begin{tabular}{rccccc}
\hline \hline No. & $\boldsymbol{x}_{\mathbf{1}}$ (degree) & $\boldsymbol{x}_{\mathbf{2}}(\mathbf{m m})$ & $\boldsymbol{x}_{\mathbf{3}}(\mathbf{m m})$ & $\mathbf{Y}_{\text {BEMF }}$ & $\mathbf{Y}_{\text {CogT }}$ \\
\hline $\mathbf{1}$ & $6^{\circ}$ & 1.0 & 1.9 & 2.85 & 0.25 \\
$\mathbf{2}$ & $8^{\circ}$ & 1.1 & 2.0 & 1.96 & 0.19 \\
$\mathbf{3}$ & $10^{\circ}$ & 1.2 & 2.1 & 1.82 & 0.095 \\
$\mathbf{4}$ & $12^{\circ}$ & 1.3 & 2.2 & 1.75 & 0.012 \\
$\mathbf{5}$ & $13^{\circ}$ & 1.4 & 2.3 & 1.58 & 0.0080 \\
$\mathbf{6}$ & $14^{\circ}$ & 1.5 & 2.4 & 1.38 & 0.0082 \\
\hline
\end{tabular}

$\mathrm{Y}_{\mathrm{BEMF}}=$ Coefficient of Back-EMF (BEMF) at $1000 \mathrm{rpm}$, $\mathrm{Y}_{\mathrm{CogT}}=$ peak to peak of cogging torque. 
The design-space to make an appropriate response surface model is screened in Table II. From the design-space, designs of experimental (DOE) are listed in Table III. A central composite design (CCD), which is one of DOE, is applied to obtain the approximate selection of the calculating points, because of providing a systematic and efficient approach in order to build the second-order fitted model. The next step in design process for the reduction of the cogging torque is to apply an optimization procedure. The constrained optimization problem can be written mathematically as follows:

\section{Minimize:}

$f(x)=Y_{\operatorname{cog} T}=0.02315 x_{1}^{2}+0.188 x_{1} x_{2}-0.3412 x_{1} x_{3}-0.03789 x_{1}-4.613 x_{2}^{2}+4.709 x_{2} x_{3}$ $+2.006 x_{2}+0.001825 x_{3}^{2}-0.03122 x_{3}+0.8408$

Where $\mathrm{f}(\mathrm{x})$ is the objective function and $\mathrm{f}(\mathrm{x})$ is estimated by the response surface model of the peak to peak value of the cogging torque.

\section{RESULTS AND DISCUSSION}

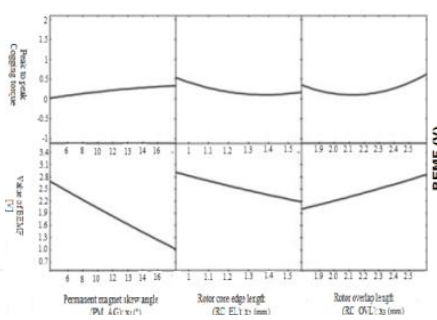

(A)

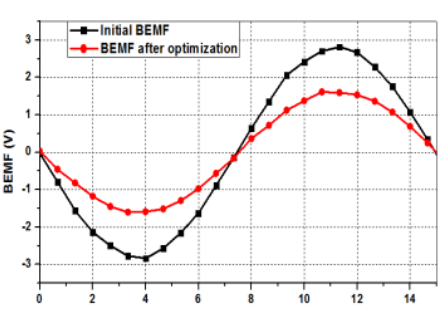

(B)
FIGURE II. (A) PREDICTION OF SECOND ORDER POLYNOMIAL MODEL. (B) BEMF COMPARISON BETWEEN INITIAL MODEL AND AFTER OPTIMIZATION.

The prediction of the second order polynomial models, which is obtained by the RSM, is illustrated in Fig. 2(a). In order to minimize the cogging torque in the design space, the value of rotor step skew angle, rotor core edge length, rotor overlap length depth turned out to be an existence. Fig.3 (a) shows the response surface of the cogging torque and (b) shows the coefficient of back EMF at $1230 \mathrm{rpm}$ according to design variables respectively. From the response surfaces of the cogging torque, the two local minimum areas turned out to be an existence. After optimization with response surface method we gets our optimum point for spoke type BLAC motor. The results of computational optimization compared with the results of the initial design are shown in Table IV. These results compare very well with those obtained using FEA analysis directly. The results of the FEA analysis correspond to optimum design variables, which is the cogging torque and torque ripple shown in Fig. 4 and the BEMF comparison between initial design and after optimization design waveform shown in Fig. 2(b). Therefore the results of the optimum design for the cogging torque reduction are contented with the demanded motor specification for the EPS application.

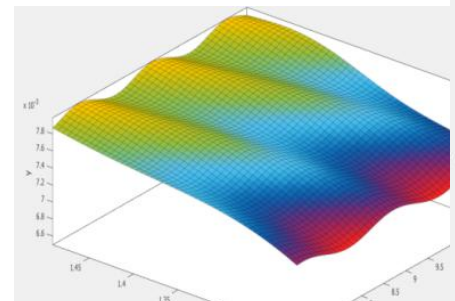

(A)

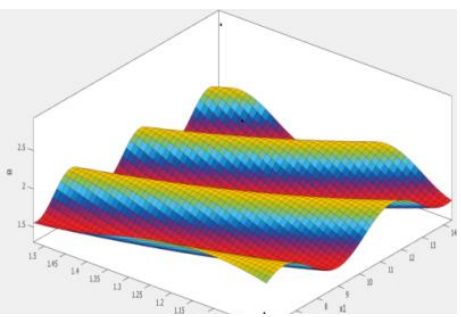

(B)
FIGURE III. (A) RESPONSE SURFACE OF THE COGGING TORQUE (B) RESPONSE SURFACE OF THE BEMF AT 1000 RPM RESPECTIVELY.

TABLE IV. COMPARISON BETWEEN INITIAL SHAPE AND OPTIMUM SHAPE.

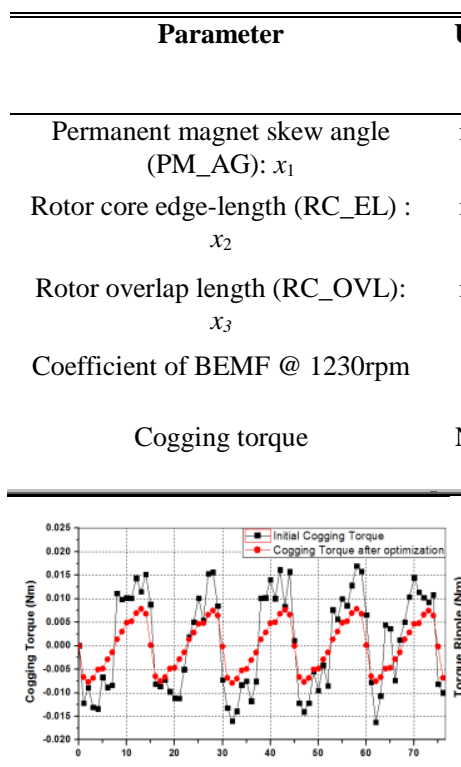

(A)

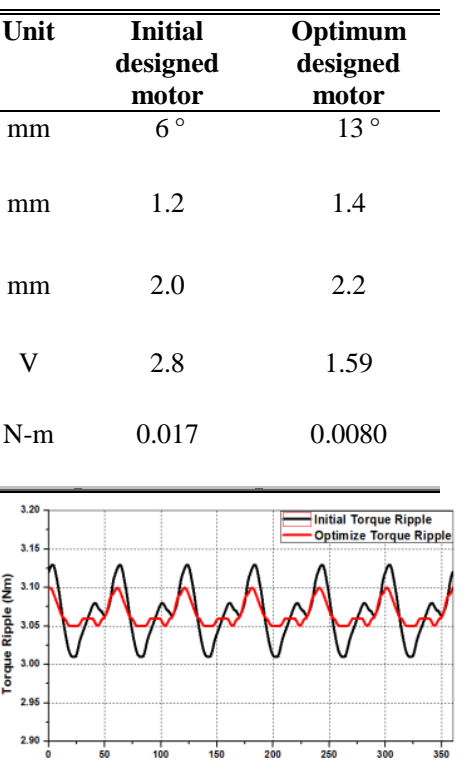

(B)
FIGURE IV. COMPARISON BETWEEN INITIAL MODEL AND AFTER OPTIMIZATION (A) COGGING TORQUE AND (B) TORQUE RIPPLE RESPECTIVELY.

\section{EXPERIMENTAL RESULTS}

The spoke type BLAC motor with optimized rotor has been prototyped for the experimental validation of the FEA results and the verification of the rotor optimization techniques for cogging torque minimization. Fig. 5 shows the photos of the assembled prototype, the optimized rotor and stator with winding. The measured and 3-D FEA predicted cogging torque and BEMF waveforms of the prototype are compared in Fig. 6. However, comparison results confirmed that cogging torque is reasonably good agreement as well BEMF. The measured cogging torque from the machine with optimize rotor is about similar than the 3-D FEA estimated one. Therefore the agreement of the predicted and measured cogging torque result is considered satisfactory. The P-P cogging torque value can be reduced from 0.017 to $0.0072 \mathrm{Nm}$ (nearly 58\%) by rotor optimization. Furthermore, a direct current motor has been used to drive the rotor of the prototype machine at rated speed in order to measure the back EMF waveforms. It can be found from Fig.6 (b) that there is relatively close agreement between the predicted and measured result. 


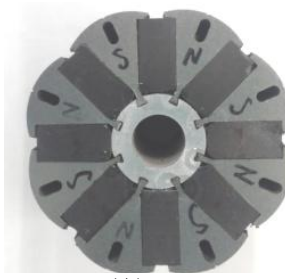

(A)

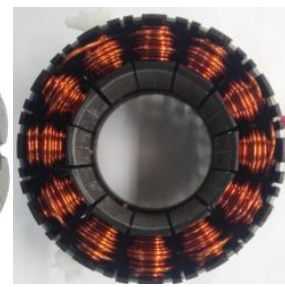

(B)

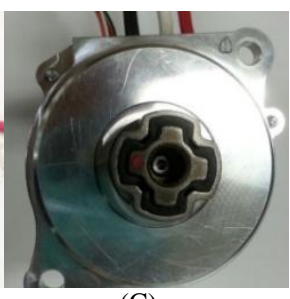

(C)
FIGURE V. (A) OPTIMIZED ROTOR, (B) STATOR WITH WINDING, (C) ASSEMBLED PROTOTYPE OF SPOKE TYPE BLAC.
(A)

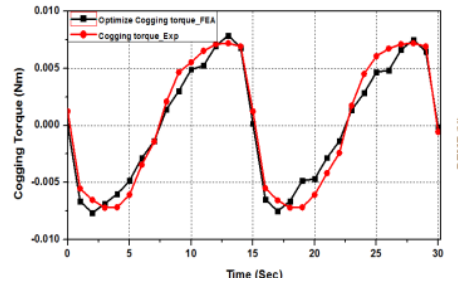

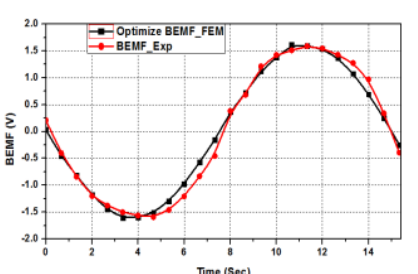

(B)
FIGURE VI. COMPARISON OF COGGING TORQUE (A) AND BEMF (B) WAVEFORMS OF THE 3-D FEA AND EXPERIMENTAL RESULTS.

\section{CONCLUSION}

This paper described the shape optimization in order to reduce the cogging torque in the SPOKE type BLAC motor. The cogging torque could be significantly alleviated by rotor optimization and step skewing techniques. The experimental results obtained from the prototype demonstrate satisfactory agreement with the estimated by FEA approaches, and underpin the findings of the study. And optimum design for the cogging torque reduction is satisfied with the required motor specification for the EPS application.

\section{ACKNOWLEDGMENT}

This research was supported by the National Research Foundation of Korea (NRF) grant funded by the Korea Government (MSIP) No: NRF- 2014R1A2A2A01003368 and by the Human Resources Development of the Korea Institute of Energy Technology Evaluation and Planning (KETEP) grant funded by the Ministry of Knowledge Economy, Republic of Korea under Grant 20134030200320.

\section{REFERENCES}

[1] D. Hanselman, Brushless Permanent-Magnet Motor Design. NewYork: McGraw-Hill, 1994.

[2] C. Bretón, J. Bartolomé, J. A. Benito, G. Tassinario, I. Flotats, C. W. Lu, and B. J. Chalmers, "'Influence of machine symmetry on reduction of cogging tor ue in permanent magnet brushless motors,"” IEEE Trans. Magn., vol. 36, no. 5, pp. 3819--3823, Sep. 2000.

[3] Z. Q. Zhu and D. Howe, ""Influence of design parameters on cogging torque in permanent magnet machines,"' IEEE Trans. Energy Convers., vol. 15 , no. 4 , pp. $407--412$, Dec. 2000.

[4] S. Wakao, T. Onuki, J. W. Im, and T. Yamamura,"“"A novel design approach for grasping broad characteristics of magnetic shield problem,"'IEEE Trans. Magn., vol. 34, no.4, pp. 2144--2146, July 1998.

[5] W.Fei and Z.Q.Zhu, "Comparison of cogging torque reduction in PM brushless machines by conventional and herringbone skewing techniques," IEEE Trans. Energy Convers., vol. 28, no. 3, Sep. 2013.

[6] Z.Q. Zhu and D. Howe, "Analytical prediction of the cogging torque in radial-field permanent magnet brushless motor," IEEE Trans.Magn., vol.28, no.2, pp. 1371-1374, Mar. 1992.
[7] J.F. Gieras, "Analytical approach to cogging torque calculation of PM brushless motor," IEEE Trans.Ind. Appl., vol.40, no.5, pp.1310-1316, Sep./Oct.2004.

[8] J. A. Guemes, A. A. Iraolagoitia, J.J.Del Hoyo, and P.Fernandez, "Torque analysis in permanent-magnet synchronous motors: a comparative study," IEEE Trans. Ind. Appl., vol. 47, no. 3, pp. 12471256, May/Jun. 2011

[9] Sang- Min Jin, Yu-Wu Zhu and Yun-Hyun Cho, "Optimal design of auxiliary poles to minimize detent force of permanent magnet linear synchronous motor," Inter. Journal of Applied Electromagnetics and Mechanics, vol.33, no.1-2/2010

[10] Y. Fujishima, S. Wakao, M. Kondo, and N. Terauchi "An optimal Design of Interior Permanent Magnet Synchronous Motor for the Next Generation Commuter Train," IEEE Trans.Magn., vol.14, no.2, pp. 1902-1905, 2004.

[11] Yu-wu Zhu, Sang-Geon Lee and Yun-hyun Cho, "Optimal design of PMLSM with low force pulsations using response surface methodology," Applied Electromagnetics and Mechanics, vol.34, ISBN, 2010.

[12] Zwe-Lee Gaing, Cin-Hsien Lin, Ming-Hsiao Tsai and Mi-Ching Tsai, "Rigorous design and optimization of brushless PM motor using response surface methodology with quantum behaved PSO operator," IEEE Trans. Magn., vol.50, No.1, January 2014. 